\title{
Physical activity and all-cause mortality across levels of overall and abdominal adiposity in European men and women: the European Prospective Investigation into Cancer and Nutrition Study (EPIC)123456
}

\section{Citation}

Ekelund, U., H. A. Ward, T. Norat, J. Luan, A. M. May, E. Weiderpass, S. J. Sharp, et al. 2015. "Physical activity and all-cause mortality across levels of overall and abdominal adiposity in European men and women: the European Prospective Investigation into Cancer and Nutrition Study (EPIC)123456." The American Journal of Clinical Nutrition 101 (3): 613-621. doi:10.3945/ ajcn.114.100065. http://dx.doi.org/10.3945/ajcn.114.100065.

\section{Published Version}

doi:10.3945/ajcn.114.100065

\section{Permanent link}

http://nrs.harvard.edu/urn-3:HUL.InstRepos:14351132

\section{Terms of Use}

This article was downloaded from Harvard University's DASH repository, and is made available under the terms and conditions applicable to Other Posted Material, as set forth at http:// nrs.harvard.edu/urn-3:HUL.InstRepos:dash.current.terms-of-use\#LAA

\section{Share Your Story}

The Harvard community has made this article openly available.

Please share how this access benefits you. Submit a story.

\section{Accessibility}




\title{
Physical activity and all-cause mortality across levels of overall and abdominal adiposity in European men and women: the European Prospective Investigation into Cancer and Nutrition Study (EPIC) ${ }^{1-6}$
}

\author{
Ulf Ekelund, Heather A Ward, Teresa Norat, Jian'an Luan, Anne M May, Elisabete Weiderpass, Stephen J Sharp, \\ Kim Overvad, Jane Nautrup Østergaard, Anne Tjønneland, Nina Føns Johnsen, Sylvie Mesrine, Agnès Fournier, Guy Fagherazzi, \\ Antonia Trichopoulou, Pagona Lagiou, Dimitrios Trichopoulos, Kuanrong Li, Rudolf Kaaks, Pietro Ferrari, Idlir Licaj, \\ Mazda Jenab, Manuela Bergmann, Heiner Boeing, Domenico Palli, Sabina Sieri, Salvatore Panico, Rosario Tumino, \\ Paolo Vineis, Petra H Peeters, Evelyn Monnikhof, H Bas Bueno-de-Mesquita, J Ramón Quirós, Antonio Agudo, \\ María-José Sánchez, José María Huerta, Eva Ardanaz, Larraitz Arriola, Bo Hedblad, Elisabet Wirfält, Malin Sund, \\ Mattias Johansson, Timothy J Key, Ruth C Travis, Kay-Tee Khaw, Sфren Brage, Nicholas J Wareham, and Elio Riboli
}

\begin{abstract}
Background: The higher risk of death resulting from excess adiposity may be attenuated by physical activity (PA). However, the theoretical number of deaths reduced by eliminating physical inactivity compared with overall and abdominal obesity remains unclear.

Objective: We examined whether overall and abdominal adiposity modified the association between PA and all-cause mortality and estimated the population attributable fraction (PAF) and the years of life gained for these exposures.
\end{abstract}

Design: This was a cohort study in 334,161 European men and women. The mean follow-up time was $12.4 \mathrm{y}$, corresponding to $4,154,915$ person-years. Height, weight, and waist circumference (WC) were measured in the clinic. PA was assessed with a validated self-report instrument. The combined associations between PA, BMI, and WC with mortality were examined with Cox proportional hazards models, stratified by center and age group, and adjusted for sex, education, smoking, and alcohol intake. Centerspecific PAF associated with inactivity, body mass index (BMI; in $\left.\mathrm{kg} / \mathrm{m}^{2}\right)(>30)$, and WC ( $\geq 102 \mathrm{~cm}$ for men, $\geq 88 \mathrm{~cm}$ for women) were calculated and combined in random-effects meta-analysis. Life-tables analyses were used to estimate gains in life expectancy for the exposures.

Results: Significant interactions $(\mathrm{PA} \times \mathrm{BMI}$ and $\mathrm{PA} \times \mathrm{WC})$ were observed, so HRs were estimated within BMI and WC strata. The hazards of all-cause mortality were reduced by $16-30 \%$ in moderately inactive individuals compared with those categorized as inactive in different strata of BMI and WC. Avoiding all inactivity would theoretically reduce all-cause mortality by $7.35 \%$ (95\% CI: $5.88 \%, 8.83 \%$ ). Corresponding estimates for avoiding obesity (BMI $>30$ ) were $3.66 \%$ (95\% CI: $2.30 \%, 5.01 \%)$. The estimates for avoiding high WC were similar to those for physical inactivity.

Conclusion: The greatest reductions in mortality risk were observed between the 2 lowest activity groups across levels of general and abdominal adiposity, which suggests that efforts to encourage even small increases in activity in inactive individuals may be beneficial to public health. Am J Clin Nutr 2015;101:613-21.

Keywords cohort study, epidemiology, obesity, physical activity, exercise, mortality, population attributable fraction

\section{INTRODUCTION}

Physical inactivity has been consistently associated with an increased risk of all-cause mortality independent of general adiposity defined by BMI (1-3). Studies that have examined the

${ }^{1}$ From the Medical Research Council (MRC) Epidemiology Unit, University of Cambridge, United Kingdom (UE, JL, SJS, SB, and NJW); the Department of Sport Medicine, Norwegian School of Sport Sciences, Oslo, Norway (UE); Imperial College, London, United Kingdom (HAW, TN, PV, HBB-d-M, and ER; University Medical Centre Utrecht, Julius Centre for Health Sciences and Primary Care, Utrecht, The Netherlands (AMM, PHP, and EM); the Department of Community Medicine, Faculty of Health Sciences, University of Troms $\varnothing$, Troms $\varnothing$, Norway (EW); the Department of Research, Cancer Registry of Norway, Oslo, Norway (EW); the Department of Medical Epidemiology and Biostatistics, Karolinska Institutet, Stockholm, Sweden (EW); Samfundet Folkhälsan, Helsinki, Finland (EW); the Section for Epidemiology, Department of Public Health, Aarhus University, Aarhus, Denmark (KO and JNØ); the Department of Cardiology, Center for Cardiovascular Research, Aalborg University Hospital, Aalborg, Denmark (KO and JNØ); Danish Cancer Society, Copenhagen, Denmark (A Tjønneland and NFJ); Inserm, Centre for Research in Epidemiology and Population Health, Nutrition, Hormones and Women's Health team, Villejuif, France (SM, AF, and GF); the Univeristy of Paris Sud, UMRS 1018, Villejuif, France (SM, AF, and GF); IGR, Villejuif, France (SM, AF, and GF); WHO Collaborating Center for Food and Nutrition Policies, Department of Hygiene, Epidemiology and Medical Statistics, University of Athens Medical School, Athens, Greece (A Trichopoulou and PL); Hellenic Health Foundation, Athens Greece (A Trichopoulou and DT); the Department of Epidemiology, Harvard School of Public Health, Boston, MA (PL and DT); the Bureau of Epidemiologic Research, Academy of Athens, Athens, Greece (PL and DT); the Division of Cancer Epidemiology, German Cancer Research Centre, Heidelberg, Germany (KL and RK); International Agency for Research on Cancer (IARC), Lyon, France (PF, IL, and MJ); the Department of Epidemiology, Deutsches Institut für Ernährungsforschung, Potsdam-Rehbrücke, Germany (MB and HB); Molecular and Nutrional Epidemiology Unit, ISPO, Cancer Prevention and Research Institute, Florence, Italy (DP); Epidemiology and Prevention Unit, Fondazione IRCCS Istituto Nazionale dei Tumori, Milano, Italy (SS); Dipartimento di Medicina Clinica e Chirurgia, Federico ii University, Naples, Italy (SP); UOS Registro Tumori e UOC Anatomia Patologica, Ospedale "Civile MP Arezzo" ASP 7, Ragusa, Italy (RT); HuGEF Foundation, Turin, Italy (PV); National Institute for Public Health and the Environment, Bilthoven, The Netherlands (HBB-d-M); the Department of Gastroenterology and Hepatology, University Medical Centre, Utrecht, The Netherlands (HBB-d-M); Public Health Directorate, Asturias, Spain (JRQ); Unit of Nutrition, Environment and Cancer, Cancer Epidemiology Research Program, Catalan Institute of 
combined associations between physical activity (PA), ${ }^{7}$ BMI, and mortality suggest that PA protects again premature death but does not eliminate the increased risk associated with high BMI (4-8). However, these previous examinations of the combined association between PA and obesity with mortality have relied on self-reported anthropometric data (5-7), have been restricted to single sex cohorts $(6,8)$, and have included only small numbers of deaths $(8,9)$, and few studies have examined PA combined with both BMI and waist circumference (WC) in relation to mortality $(5,8,9)$. Furthermore, those that have examined the combined associations between PA, adiposity, and mortality have used a dichotomous categorization of PA and BMI (9), leaving uncertainty about whether PA protects against premature deaths across established BMI and WC categories $(10,11)$.

Whereas it could be hypothesized that PA exerts its influence on mortality indirectly through reducing adiposity, recent data from the European Prospective Investigation into Cancer and Nutrition (EPIC) suggest that PA is unrelated to change in body

Oncology, Barcelona, Spain (AA); Andalusian School of Public Health, Granada, Spain (M-JS); CIBER de Epidemiología y Salud Pública (CIBERESP), Spain (M-JS, JMH, and EA); the Department of Epidemiology, Murcia Regional Health Council, Murcia, Spain (JMH); Navarre Public Health Institute, Pamplona, Spain (EA); Public Health Division of Gipuzkoa, Instituto BIODonostia, Basque Government, CIBER Epidemiología y Salud PúblicaCIBERESP, Spain (LA); Cardiovascular Epidemiology (BH) and Nutritional Epidemiology (EW), Department of Clinical Sciences, Lund University, Malmö, Sweden; the Department of Public Health and Clinical Medicine, Umeå University, Umeå, Sweden (MS and MJ); Cancer Epidemiology Unit, Nuffield Department of Clinical Medicine, University of Oxford, Oxford, United Kingdom (TJK and RCT); and Clinical Gerontology Unit, University of Cambridge, Cambridge, United Kingdom (K-TK).

${ }^{2}$ The EPIC is supported by grants from the European Commission: Public Health and Consumer Protection Directorate 1993-2004; Research DirectorateGeneral 2005-present; Deutsche Krebshilfe; German Cancer Research Center; German Federal Ministry of Education and Research; Danish Cancer Society; Health Research Fund of the Spanish Ministry of Health (Network of Centers of Research in Epidemiology and Public Health C03/09); the Spanish Regional Governments of Andalucia, Asturias, Basque Country, Murcia, and Navarra; Cancer Research United Kingdom; Medical Research Council, United Kingdom; the Stroke Association, United Kingdom; British Heart Foundation; Department of Health, United Kingdom; Food Standards Agency, United Kingdom; the Wellcome Trust, United Kingdom; Greek Ministry of Health and Social Solidarity and Hellenic Health Foundation; Greek Ministry of Education; Italian Association for Research on Cancer; Dutch Ministry of Public Health, Welfare, and Sports; National Cancer Registry and the Regional Cancer Registries Amsterdam, East, and Maastricht of the Netherlands; World Cancer Research Fund; Statistics Netherlands; Swedish Cancer Society; Swedish Scientific Council; Regional Government of Skåne, Sweden; French League Against Cancer; the 3M Company; Mutuelle Generale de l'Education Nationale, France; Institut Gustave Roussy, France; and Institut National de la Sante et de la Recherche Medicale, France. UE, JL, SJS, SB, and NJW were funded by the MRC Epidemiology Unit Programmes (MC_UU_12015/1 and MC_UU_12015/4). This is an open access article distributed under the CC-BY license (http://creativecommons.org/licenses/by/3.0/).

${ }^{3}$ Supplemental Tables 1-7 are available from the "Supplemental data" link in the online posting of the article and from the same link in the online table of contents at http://ajen.nutrition.org.

${ }^{4} \mathrm{UE}$ and HAW are joint first authors.

${ }^{5} \mathrm{NJW}$ and ER contributed equally to this work.

${ }^{6}$ Address correspondence to U Ekelund, MRC Epidemiology Unit, University of Cambridge, Box 285, Addenbrooke's Hospital, Hills Road, Cambridge, CB2 0QQ, United Kingdom. E-mail: ulf.ekelund@mrc-epid.cam.ac.uk.

${ }^{7}$ Abbreviations used: EPIC, European Prospective Investigation into Cancer and Nutrition; PA, physical activity; PAEE, physical activity energy expenditure; PAF, population attributable fraction; WC, waist circumference.

Received September 24, 2014. Accepted for publication December 12, 2014. First published online January 14, 2015; doi: 10.3945/ajcn.114.100065. weight and inversely, albeit weakly, associated with change in WC (12). Thus, PA may interact differentially with BMI and WC in relation to all-cause mortality.

We therefore examined the associations between PA and allcause mortality and whether BMI and WC modified these associations in a large sample of 334,161 men and women followed for $>12$ y from the EPIC study, in which both BMI and WC were measured during clinical examinations at baseline. As a secondary aim we estimated how many deaths could theoretically be avoided if inactive or obese individuals were more active or nonobese, respectively, and calculated the years of gain in life expectancy from avoiding physical inactivity, high BMI (in $\mathrm{kg} / \mathrm{m}^{2} ; \geq 30$ ), and high WC $(>88 \mathrm{~cm}$ and $>102 \mathrm{~cm}$ in women and men), separately and combined in the cohort.

\section{METHODS}

\section{The EPIC cohort}

EPIC is a multicenter prospective cohort study, which recruited 519,978 volunteers from 23 centers in 10 countries [Sweden, Denmark, Norway, The Netherlands, United Kingdom, France, Germany, Spain, Italy, and Greece] between 1992 and 2000. The study population included volunteers aged mostly $25-70 \mathrm{y}$ at the time of recruitment and has been described in detail previously $(13,14)$. There were 518,408 participants for whom vital statistics were available at the end of follow-up (2010). Individuals who reported either baseline heart disease $(n=6256)$, stroke $(n=3485)$, cancer $(n=$ $15,926)$ or a combination of these conditions $(n=1092)$ were excluded from the analysis. Participants who were missing data on PA were excluded $(n=45,725)$; this included the entire cohort from Norway $(n=36,920)$ as the information collected on leisure-time PA was not compatible with the other EPIC centers questionnaires. Participants in the top and bottom 0.5 th percentile of the energy intake to estimated basal metabolic rate ratio were excluded $(n=8637)$ because of unrealistic dietary intake information, as were those with missing data on the following covariates: height and weight $(n=54,522)$, WC $(n=28,548)$, alcohol $(n=478)$, education $(n=12,276)$, and smoking $(n=3031)$. Participants with extreme anthropometric measurements (height $<130 \mathrm{~cm}$, weight $>250 \mathrm{~kg}, \mathrm{BMI}<18.5$, WC $<40 \mathrm{~cm}$, WC $>160 \mathrm{~cm}$, or BMI $>25$ and $\mathrm{WC}<60 \mathrm{~cm})$ were additionally excluded $(n=4271)$. The current analysis therefore included all participants $(n=$ 334,161 ) for whom measured height, weight, and WC were available. A detailed comparison between excluded and included participants is available elsewhere (Supplemental Table 1).

To maintain sample size per center without combining groups considered to be too heterogeneous with respect to lifestyle characteristics, the 23 EPIC centers were analyzed as the following 11 groups in the current analysis: France, Italy, Spain, United Kingdom health conscious (Oxford participants recruited through the Vegetarian Society), United Kingdom general (all United Kingdom participants not included in the Health Conscious group), The Netherlands, Greece, Heidelberg, Potsdam, Sweden, and Denmark (14). The study was approved by the Institutional Review Board at the International Agency for Research on Cancer 
and local ethics committees, and informed consent forms were signed at each local center.

\section{Assessment of physical activity}

Data on occupational, recreational, and household PA during the past year either were obtained from an in-person interviews or were self-administered by using a standardized questionnaire. Participants reported their level of occupational PA as either sedentary (e.g., office work), standing (e.g., hairdresser, guard), physical work (e.g., plumber, nurse), or heavy manual work (e.g., construction worker, bricklayer). The Cambridge Index of PA was derived by combining occupational activity level with recreational activity, as assessed by the amount of time in hours per week during winter and summer spent cycling and in other physical exercises (e.g., jogging, swimming) and is summarized into 4 groups: active, moderately active, moderately inactive, and inactive $(15,16)$.

We examined the validity of the Cambridge Index in an independent substudy in 1941 men and women similar in age to those in the original EPIC cohort, across all 10 EPIC countries by using combined movement and heart rate monitoring as the criterion (16). PA energy expenditure (PAEE) increased significantly by increasing categories of self-reported PA $(P$-trend $<$ 0.0001 ), with a significant correlation between measured PAEE and the categorical PA index (Spearman correlation $=0.33, P<$ 0.013). Further calibration results suggest that the average PAEE across categories of PA were as follows: inactive (36 kJ/kg daily); moderately inactive $(41 \mathrm{~kJ} / \mathrm{kg}$ daily); moderately active $(46 \mathrm{~kJ} / \mathrm{kg}$ daily), and active (51 kJ/kg daily). The format of the PA questions was somewhat different in Naples (Italy) relative to the other centers in the current analysis; however, the data from Naples were transformed for inclusion in the PA index. In Umeå (Sweden), a 4-level PA variable was derived from cross-tabulation of occupational and exercise; owing to the similarity with the Cambridge categories (inactive, moderately inactive, moderately active, active) (16), the Umeå classification has been incorporated into the current analysis.

\section{Assessment of anthropometric measures}

Body weight (in $\mathrm{kg}$ ) and height (in $\mathrm{cm}$ ) were measured at baseline according to standardized procedures without shoes (17). Self-reported anthropometric data (Oxford) were adjusted by using prediction equations derived from the general population, where a subset of participants had both self-reported and measured anthropometric data available $(17,18$ ). WC (in $\mathrm{cm}$ ) was measured at the narrowest torso circumference or at the midpoint between the lower ribs and iliac crest. Weight measurements were corrected to account for protocol differences between centers as previously described (18). BMI was calculated as body weight (in $\mathrm{kg}$ ) divided by height squared (in $\mathrm{m}$ ). Individuals were categorized into normal-weight (BMI: 18.524.9), overweight (BMI: 25-30), and obese (BMI $\geq 30$ ). Participants were dichotomized by WC values by using the cutoffs of $\geq 102 \mathrm{~cm}$ among men and $\geq 88 \mathrm{~cm}$ among women.

\section{Assessment of endpoints}

Mortality data were obtained at the regional or national level. In Denmark, Italy, The Netherlands, Spain, Sweden, and the United Kingdom, vital status and the causes and the dates of death were ascertained by death indexes, cancer registry records, and national health statistics. Active follow-up was adopted in Germany, Greece, and France. Causes of death were coded according to the International Classification of Diseases, 10th Revision (19). The endpoint in the current analysis was death from all causes collected between 2008 and 2010, depending on the center.

\section{Statistical analysis}

We examined the associations between PA, adiposity, and all-cause mortality using Cox regression models to obtain HRs. The baseline hazard function of the models was stratified by center and age, with age categorized as $<25 \mathrm{y}$, then every 5-y age group, and $\geq 75 \mathrm{y}$. Significant interactions $(\mathrm{PA} \times \mathrm{BMI}$ and PA $\times$ WC) were observed with respect to all-cause mortality $(P<0.005)$. HRs were therefore estimated within strata defined by BMI (3 groups according to WHO classification) and WC ( 2 groups, cutoffs: $\geq 102 \mathrm{~cm}$ for men and $\geq 88 \mathrm{~cm}$ for women). Two sets of covariates were included in the models: 1) sex; 2) sex, lifestyle (alcohol intake and smoking), and demographic covariates (education). The lifestyle and demographic characteristics selected a priori were education (none/primary school, technical/professional, secondary, and longer education), alcohol intake (baseline: $0,>0-6,>6-12$, $>12-24,>24-60$, and $>60 \mathrm{~g} / \mathrm{d}$ ), and smoking (current, former, and never). In addition to the main covariates described above, potential dietary confounders were evaluated for inclusion in the Cox regression models. However, none of the dietary variables tested [fiber $(\mathrm{g} / \mathrm{d})$, energy $(\mathrm{kcal} / \mathrm{d})$, dairy $(\mathrm{g} / \mathrm{d})$, red meat $(\mathrm{g} / \mathrm{d})$, and fish $(\mathrm{g} / \mathrm{d})$; crude and adjusted for energy intake by using both the standard and residual methods] yielded an important change $(<10 \%)$ in the HR estimates for the PA and adiposity exposure variables and were therefore not included. Similarly, stratification of the highest BMI group into 2 groups (30-34.9 and $\geq 35$ ) yielded similar estimates in each group and are therefore not presented.

We estimated center-specific RRs by comparing levels of physical inactivity, general and abdominal obesity_adjusted for sex, education, smoking, and alcohol intake-using binomial regression. We also estimated RRs adjusted for BMI. Adjusted RRs were used to calculate the population attributable fraction (PAF):

$$
P A F=p_{d}\left(\frac{R R-1}{R R}\right)
$$

Where $p_{d}$ is the proportion of deaths exposed to the risk factor of interest, and $R R$ is the adjusted RR (20). The STATA command "punafcc" was used to calculate the PAFs and 95\% CIs. PAFs were thereafter combined by using a randomeffect meta-analysis to assess the proportion of mortality that could have been averted by avoiding the following risk factors: inactivity (all inactive individuals become at least moderately inactive, i.e., moving from category 1 to category 2 or higher of the Cambridge Index), high BMI [all individuals classified as obese (BMI $\geq 30$ ) become nonobese], and high $\mathrm{WC}$ ( $\geq 88 \mathrm{~cm}$ and $\geq 102 \mathrm{~cm}$ in women and men, respectively). These analyses were adjusted for the same covariates used 
above. Gain in life expectancy was calculated from life tables (21).

Analyses within subgroups defined by sex, age group, and smoking status and a sensitivity analysis that excluded the first $3 \mathrm{y}$ of follow-up (3116 participants were excluded, of whom 2317 were deceased) - to minimize the possibility of reverse causation due to underlying disease-were performed. All analyses were performed by using STATA 12 statistical software (StataCorp LP).

\section{RESULTS}

A total of 116,980 men (mean age 52.6 y) and 217,181 women (mean age $51.2 \mathrm{y}$ ) were included in the current analysis (Tables 1 and 2; Supplemental Table 1 and Supplemental Table 2). Across all centers, the mean follow-up time was $12.4 \mathrm{y}$, corresponding to $4,154,915$ person-years. There were 11,086 deaths among men and 10,352 deaths among women.

Within the BMI strata, the hazard of all-cause mortality was reduced by $20-30 \%$ across groups when the moderately inactive individuals were compared with the inactive individuals (the reference group). In normal-weight and overweight individuals, higher levels of PA were associated with further reduction in hazards, which were most pronounced in the normal-weight group, i.e., decreased by $41 \%$ in those categorized as active compared with those categorized as inactive. In contrast, in those with a BMI $>30$, no further reduction in hazard was observed with increasing levels of PA beyond that for the moderately inactive group. Adjustment for additional covariates did not materially change these estimates (model 2;

Table 3).

Similar results were observed when participants were stratified according to abdominal adiposity (WC $\geq 88 \mathrm{~cm}$ and $\geq 102 \mathrm{~cm}$ in women and men, respectively). The most pronounced decreased hazard was observed between the inactive (reference) and moderately inactive groups in both the abdominally lean (HR: $0.75 ; 95 \%$ CI: $0.72,0.78$ ) and abdominally obese (HR: $0.79 ; 95 \%$ CI: $0.75,0.84$ ) groups. A further reduction in hazard across PA groups was observed in abdominally lean but not in abdominally obese groups (Table 3). Results were similar within subgroups defined by sex, age, and smoking status (Supplemental Tables 3-5).

Similar to overall activity, higher levels of recreational activity was associated with lower HRs of all-cause mortality independent of covariates in each BMI and WC group; however, occupational activity was not related to mortality in working individuals (Supplemental Table 6).

If all inactive individuals were at least moderately inactive, the number of deaths would theoretically be reduced by $7.35 \%$ (95\% CI: $\left.5.88,8.83 ; I^{2}: 70.2 \% ; P<0.001\right)$ (Figure 1A), and life expectancy at birth would increase by 0.70 y $(95 \% \mathrm{CI}$ : $0.56,0.84)$. These estimates were only marginally attenuated by additional adjustment for BMI $\left(I^{2}: 70.7 \%\right.$; PAF: $7.08 \%$; $95 \%$ CI: $5.58,8.58$ ). Comparable estimates for obesity (BMI $>30$ ) were lower: $3.66 \%$ (95\% CI: $2.30,5.01 ; I^{2}: 82.5 \% ; P<$ 0.001 ; Figure 1B) and 0.34 y (95\% CI: $0.21,0.48)$, which suggests that physical inactivity is responsible for more than twice as many deaths as general obesity in this European population. Finally, we calculated the PAF and gain in life

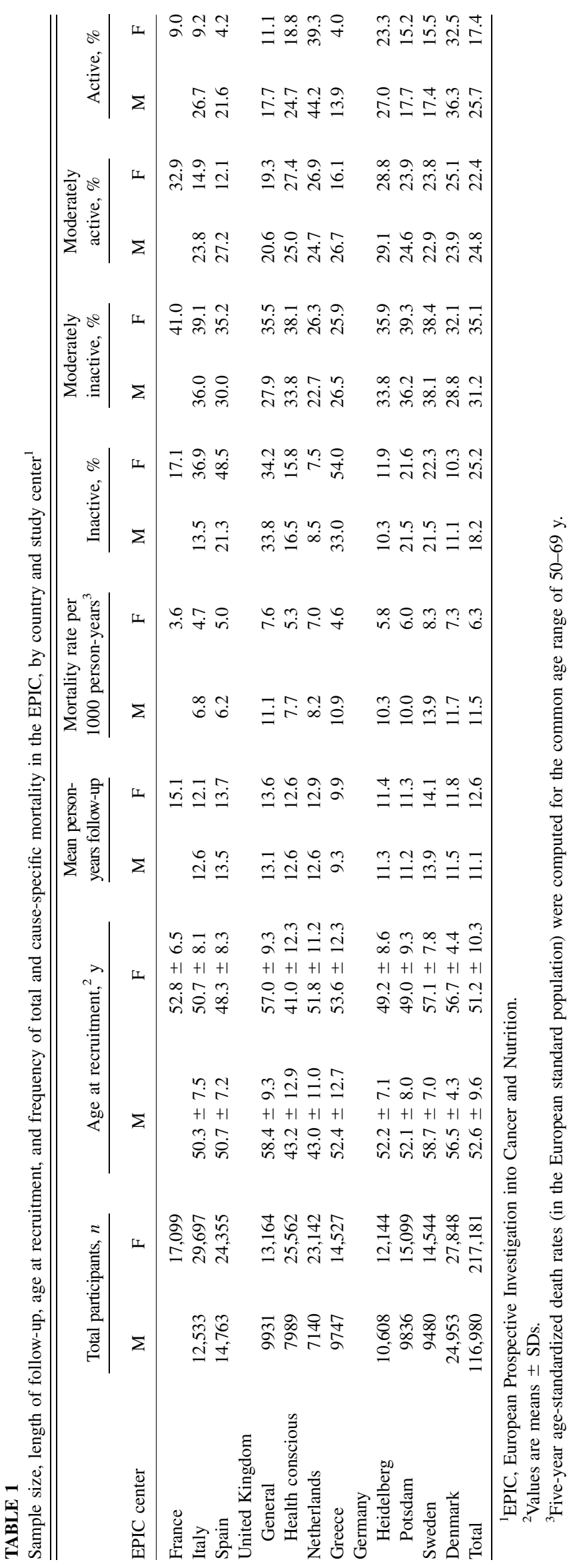


TABLE 2

Anthropometric, lifestyle, and demographic characteristics of the EPIC cohort across levels of physical activity, by sex ${ }^{1}$

\begin{tabular}{|c|c|c|c|c|c|c|c|c|c|c|}
\hline & \multicolumn{5}{|c|}{ Men } & \multicolumn{5}{|c|}{ Women } \\
\hline \multicolumn{11}{|l|}{ BMI } \\
\hline $18.5-24.9 \mathrm{~kg} / \mathrm{m}^{2}$ & 40,006 & 28.7 & 34.4 & 35.1 & 37.1 & 113,216 & 37.5 & 54.1 & 59.5 & 59.9 \\
\hline $25-29.9 \mathrm{~kg} / \mathrm{m}^{2}$ & 58,005 & 50.2 & 49.9 & 49.6 & 49.1 & 69,981 & 36.8 & 32.0 & 29.2 & 29.8 \\
\hline $30-34.9 \mathrm{~kg} / \mathrm{m}^{2}$ & 16,290 & 17.7 & 13.6 & 13.4 & 12.1 & 25,196 & 18.2 & 10.5 & 8.7 & 8.0 \\
\hline$<88(\mathrm{~F}) /<102(\mathrm{M})$ & 89,938 & 68.0 & 76.6 & 78.7 & 81.7 & 164,928 & 63.3 & 78.1 & 81.9 & 82.1 \\
\hline$\geq 88(\mathrm{~F}) / \geq 102(\mathrm{M})$ & 27,042 & 32.0 & 23.4 & 21.3 & 18.3 & 52,253 & 36.8 & 21.9 & 18.1 & 17.8 \\
\hline \multicolumn{11}{|l|}{ Alcohol } \\
\hline $0 \mathrm{~g} / \mathrm{d}$ & 7646 & 10.9 & 5.7 & 5.6 & 5.3 & 37,317 & 30.5 & 15.2 & 11.4 & 9.4 \\
\hline$>0-6 \mathrm{~g} / \mathrm{d}$ & 23,823 & 24.0 & 20.0 & 18.9 & 19.7 & 87,963 & 38.2 & 41.0 & 41.4 & 41.6 \\
\hline$>6-12 \mathrm{~g} / \mathrm{d}$ & 18,952 & 15.6 & 16.5 & 16.2 & 16.2 & 39,013 & 13.3 & 18.3 & 20.1 & 21.3 \\
\hline Never & 36,836 & 28.1 & 32.1 & 32.3 & 32.3 & 124,251 & 63.4 & 57.1 & 55.6 & 50.7 \\
\hline Former & 43,575 & 38.0 & 37.6 & 36.9 & 36.7 & 48,851 & 16.5 & 22.8 & 25.1 & 27.4 \\
\hline Smoker & 36,569 & 33.9 & 30.3 & 30.7 & 31.1 & 44,079 & 20.2 & 20.2 & 19.4 & 21.9 \\
\hline \multicolumn{11}{|l|}{ Education } \\
\hline None/primary school & 41,129 & 39.9 & 29.4 & 35.6 & 38.4 & 76,142 & 54.7 & 31.9 & 25.6 & 25.2 \\
\hline Technical/professional & 28,908 & 21.4 & 22.6 & 24.8 & 29.6 & 54,216 & 17.2 & 25.3 & 26.6 & 33.5 \\
\hline Secondary & 13,702 & 12.0 & 13.6 & 11.0 & 9.9 & 38,295 & 13.9 & 18.6 & 19.8 & 18.4 \\
\hline Longer education & 33,241 & 26.8 & 34.4 & 28.7 & 22.1 & 48,528 & 14.2 & 24.2 & 28.0 & 23.0 \\
\hline
\end{tabular}

${ }^{1}$ EPIC, European Prospective Investigation into Cancer and Nutrition.

expectancy for avoiding high WC $(>88 \mathrm{~cm}$ and $\geq 102 \mathrm{~cm}$ in women and men, respectively), and the estimate was similar to that for inactivity: $6.53 \%$ (95\% CI: 4.90, 8.15) (Figure 1C), corresponding to an estimated gain in life expectancy of 0.62 y (95\% CI: 0.46, 0.79). The combined PAFs and estimated gains in life expectancy for inactivity and BMI and high WC are shown in Figure 2A, B and Figure 3A, B. Supplemental Table 7 shows the proportion of deaths exposed to physical inactivity, general obesity, and abdominal obesity and the respective adjusted RRs by study center.

TABLE 3

HRs and $95 \%$ CIs of all-cause mortality in relation to physical activity levels within strata of BMI and waist circumference groups ${ }^{1}$

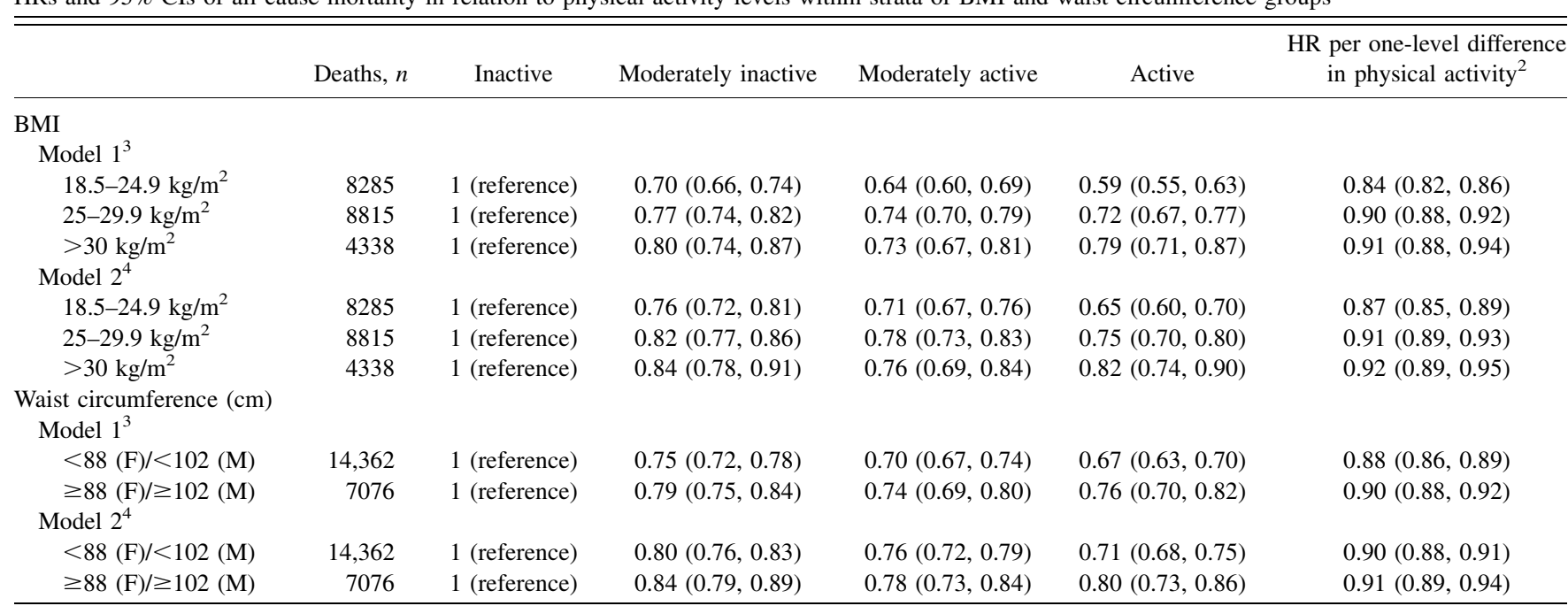

${ }^{1}$ Data were analyzed by Cox regression models.

${ }^{2}$ Physical activity variables entered into the model as an ordinal variable.

${ }^{3}$ Model 1: adjusted for sex; stratified by age at recruitment and study center. For waist circumference, sex was included as a stratum variable rather than as a covariate to meet the proportional hazards assumption.

${ }^{4}$ Model 2: adjusted as for model 1 and for education, smoking, and alcohol. 
A

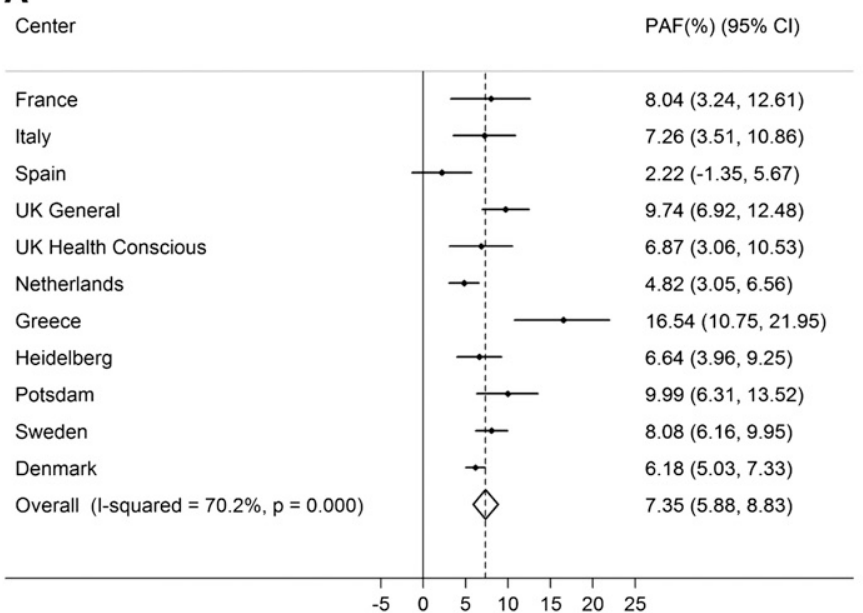

$\mathbf{C}_{\text {Center }}$

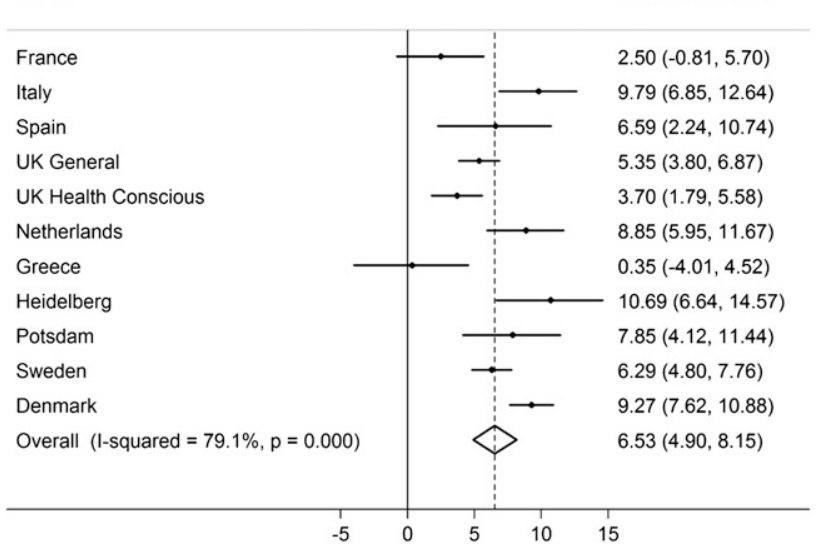

B

Center

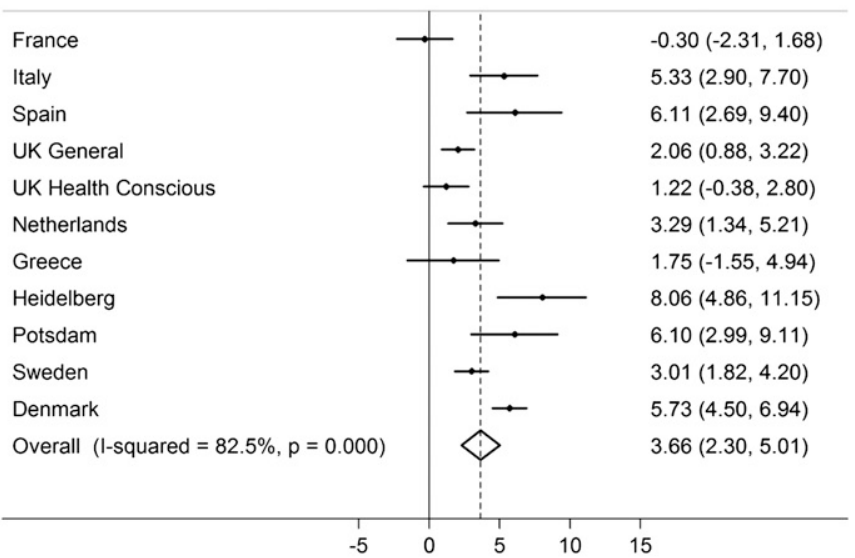

FIGURE 1 Proportion of deaths averted when all inactivity (lowest category of the Cambridge Index; A), general obesity [BMI (in kg/m²) $>30 ; \mathrm{B}]$, and abdominal obesity ( $\geq 88 \mathrm{~cm}$ and $\geq 102 \mathrm{~cm}$ in men and women, respectively; $\mathrm{C}$ ) were removed. Data were adjusted for age, sex, education, smoking, and alcohol intake $(n=334,161)$. PAF, population attributable fraction.

\section{DISCUSSION}

PA is inversely associated with all-cause mortality at all levels of BMI and WC. The greatest reduction in risk was observed in the comparison of inactive and moderately active groups.
Physical inactivity may theoretically be responsible for twice as many total deaths as high BMI $(\geq 30)$ in this population, similar to the number of deaths averted if abdominal adiposity were eliminated.
A

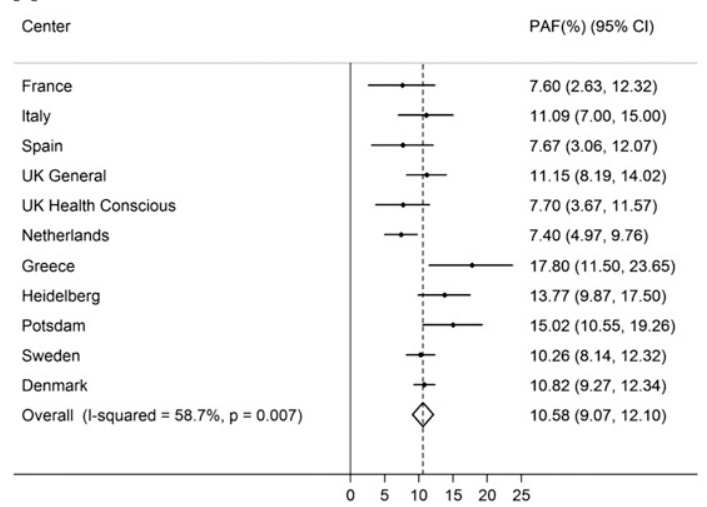

B

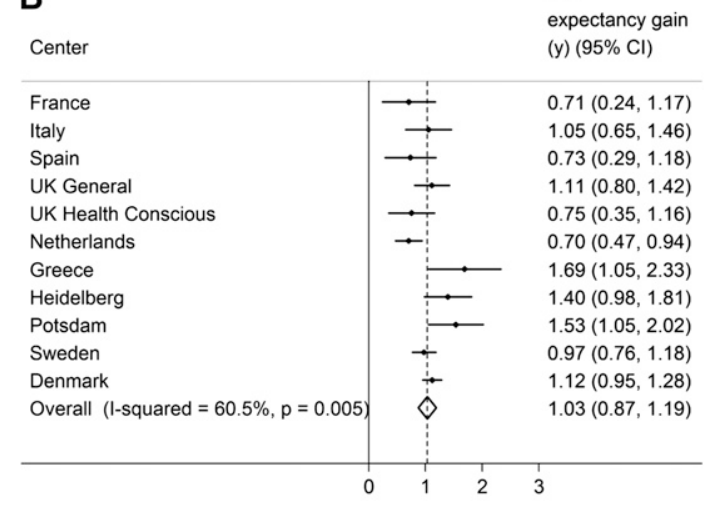

FIGURE 2 The combined proportion of number of deaths theoretically averted when all inactivity (lowest category of Cambridge Index) and general obesity [BMI (in $\mathrm{kg} / \mathrm{m}^{2}$ ) $>30$ ] were removed (A) and estimated life expectancy gain when all inactivity and general obesity were avoided (B). Data were adjusted for age, sex, education, smoking, and alcohol intake $(n=334,161)$. PAF, population attributable fraction. 
A

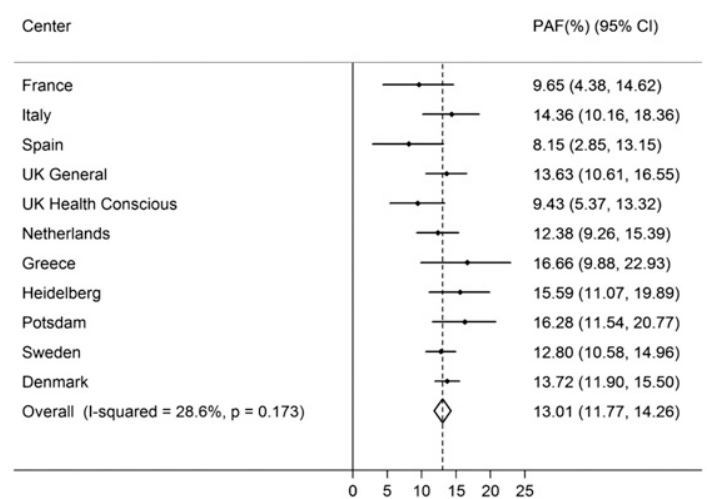

B

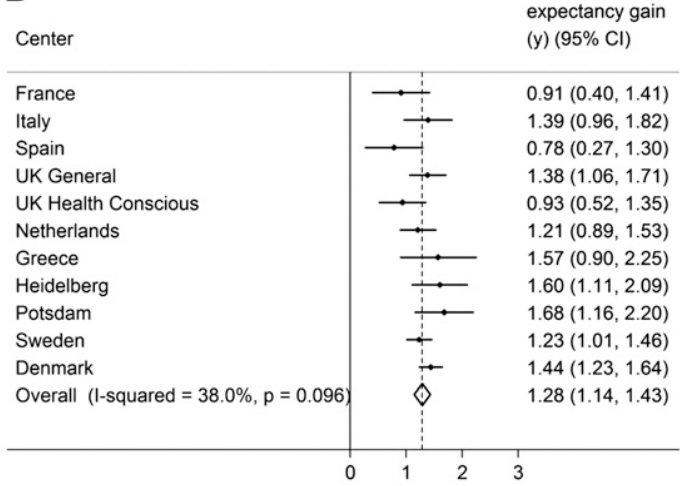

FIGURE 3 The combined proportion of number of deaths averted when all inactivity (lowest category of Cambridge Index) and abdominal obesity ( $\geq 88$ $\mathrm{cm}$ and $\geq 102 \mathrm{~cm}$ in women and men, respectively) were avoided (A) and estimated life expectancy gain when all inactivity and abdominal obesity were avoided (B). Data were adjusted for age, sex, education, smoking, and alcohol intake $(n=334,161)$. PAF, population attributable fraction.

We observed significant interactions between PA and BMI and WC in relation to all-cause mortality. The most pronounced risk reductions by increasing levels of PA were observed in those categorized as normal weight and abdominally lean. However, across all strata for both general and abdominal adiposity, a markedly reduced hazard was observed between those categorized as inactive and those categorized as moderately inactive. Data from the United States suggest that PA reduces but does not eliminate the increased risk of adiposity on all-cause mortality when cross-classifying activity and BMI groups $(5,6)$. Others have shown that exercising for $15 \mathrm{~min} / \mathrm{d}$ (defined as the low-volume exercise group) is associated with a $14 \%$ reduction in risk of all-cause mortality compared with inactivity in an Asian population (2). Our results extend these previous observations to also include European men and women and suggest that, within each strata for BMI and WC, the hazard of allcause mortality was substantially reduced when the inactive group was compared with the moderately inactive group. Thus, emerging evidence is accumulating indicating that substantial health benefits may be achieved by fairly small increases in PA.

Results from our calibration study suggest that moving from one category to the next (e.g., from the inactive to the moderately inactive group) is associated with an increase in PAEE of between 90 and $110 \mathrm{kcal} / \mathrm{d}$ in men and women with a similar BMI, as in the EPIC cohort (16). Assuming that all inactive individuals were truly inactive and did not participate in moderate and vigorous intensity, this amount of energy expenditure can be achieved by an increase in PAEE equivalent to $\sim 20$ min of brisk walking per day, which is lower than the current PA recommendations for public health (22-24).

Approximately 9.2 million deaths occurred in European men and women in 2008 (25), of which-according to our estimates from the current study-676,000 deaths may be attributable to physical inactivity compared with 337,000 deaths attributable to obesity (BMI >30). Our PAF estimates were derived directly from the RR estimates in the EPIC population, prevalence data using measured exposures and based on theoretically avoiding high BMI $(\geq 30)$, and all physical inactivity (the inactive category from the Cambridge Index)—more likely achievable in population-wide public health campaigns.

Our estimate of gain in life expectancy for PA is similar to that from Lee et al. (3) but lower than that from other comparable studies $(2,4,26)$. The differences between studies are likely explained by differences in the assessment and the prevalence of the risk factors and RRs between populations, different calculations of PAFs, and differences in subsequent gains in life expectancy. In this cohort, the proportions of people at risk were $22.7 \%$ for inactivity, $15.8 \%$ for obesity, and $21.9 \%$ for high WC. These prevalence estimates, and hence the estimates of PAF, may differ between populations. However, the advantage of examining the PAFs for these risk factors within a single cohort using the observed prevalence estimates is the ability to compare the relative importance of physical inactivity and central and general obesity. Our results suggest that the influence of physical inactivity on mortality appears to be greater than that of high BMI and similar to that of high WC in European men and women.

Our results should be interpreted keeping the following limitations in mind. We observed significant heterogeneity in PAF estimates across centers. Apart from differences in RR estimates and the prevalence of risk factors between centers, heterogeneity was mainly explained by the Greek center (in men), where the risk of death associated with general and abdominal obesity was inverse in combination with the highest PAF for physical inactivity; by the French cohort (women only), in which neither general nor abdominal obesity was associated with an increased risk of premature death; and by the Spanish center (in women), in which no association between PA and mortality was observed.

Furthermore, whereas BMI and WC may both be indicators of total fat mass rather than general and abdominal adiposity, respectively (27), prospective observational studies consistently suggest a higher risk of mortality associated with high WC than with high BMI (28-30). From a public health perspective, it is therefore encouraging that our results suggest that small increases in PA in those who are currently categorized as inactive appear to be associated with significant reductions in all-cause mortality at all levels of BMI and WC.

The strengths of this study included its prospective design and its large number of participants, for whom measured height, weight, and $\mathrm{WC}$ values spanned a wide range. The large sample size and long follow-up facilitated exclusion of early years of follow-up in the sensitivity analysis. This minimized the likelihood of confounding resulting from low activity in lean participants with subclinical disease. A broad range of covariates 
permitted the evaluation of potential confounders, such as diet, smoking history, and alcohol intake. HRs, PAFs, and gains in life expectancy were estimated by using a validated measure of PA (16). Obesity was defined on the basis of measured height, weight, and WC, which eliminated misclassification bias. Although our global measure of PA has been validated (16), it is still a relatively imprecise way of characterizing activity. However, the impact of nondifferential misclassification would be to attenuate the association between activity and mortality. Thus, our results are more likely to underestimate the true importance of PA rather than to accentuate it. The same is not true for obesity, because it is more accurately measured; thus, the estimates of the association reported here are more likely to reflect the true underlying association.

EPIC Europe is a population-based study, but it was never intended to be entirely representative of the adult European population. Representativeness matters considerably in attempts to generalize prevalence estimates of an exposure or a disease, but it is much less of an issue in the interpretation of measures of association in a cohort study, provided the full range of exposures is observed in the population. Despite not being entirely representative, the prevalence of obesity in our sample is similar to that reported for European men and women (31). We considered the possibility of confounding by co-existent disease among participants by adjusting for comorbidities and excluding deaths in the first $3 \mathrm{y}$ of follow-up. PA and anthropometric measures were assessed only at baseline; therefore, the current analysis did not take into consideration changes in PA and anthropometric measures over time.

The greatest reductions in all-cause mortality risk were observed between the inactive and the moderately inactive groups across levels of general and abdominal adiposity, which suggests that efforts to encourage even small increases in activity in inactive individuals may be of public health benefit. The hypothetical number of deaths reduced by avoiding inactivity in this population may be double that with an approach that avoided high BMI and similar to that of an approach that avoided high WC.

The authors' responsibilities were as follows-UE and HAW: conceived the idea, drafted the manuscript, had full access to all the data in the study, and took responsibility for the integrity of the data and the accuracy of the data analysis; HAW and JL: performed the statistical analyses; UE, HAW, TN, AMM, EW, SB, SJS, and NJW: interpreted the results; and KO, JNØ, A Tjønneland, NFJ, SM, AF, GF, A Trichopoulou, PL, DT, KL, RK, PF, IL, MJ, MB, HB, DP, SS, SP, RT, PV, PHP, EM, HBB-d-M, JRQ, AA, M-JS, JMH, EA, LA, BH, EW, MS, MJ, TJK, RCT, K-TK, ER (EPIC investigators): conducted the research and were responsible for the study design and data collection. All authors critically revised the manuscript for intellectual content and approved the final version of the manuscript. The funders had no role in the design and conduct of the study; collection, management, analysis, and interpretation of the data; or preparation, review, or approval of the manuscript. No potential conflicts of interest relevant to this article were reported.

\section{REFERENCES}

1. Paffenbarger RS Jr., Hyde RT, Wing AL, Hsieh CC. Physical activity, all-cause mortality and longevity of college alumni. N Engl J Med 1986;314:605-13.

2. Wen CP, Wai JP, Tsai MK, Yang YC, Cheng TY, Lee MC, Chan HT, Tsao CK, Tsai SP, Wu X. Minimum amount of physical activity for reduced mortality and extended life expectancy: a prospective cohort study. Lancet 2011;378:1244-53.
3. Lee IM, Shiroma EJ, Lobelo F, Puska P, Blair SN, Katzmarzyk PT Lancet Physical Activity Series Working Group. Effect of physical inactivity on major non-communicable diseases worldwide: an analysis of burden of disease and life expectancy. Lancet 2012;380:219-29.

4. Moore SC, Patel AV, Matthews CE, Berrington de Gonzalez A, Park Y, Katki HA, Linet MS, Weiderpass E, Visvanathan K, Helzlsouer KJ, et al. Leisure time physical activity of moderate to vigorous intensity and mortality: a large pooled cohort analysis. PLoS Med 2012;9:e1001335.

5. Koster A, Harris TB, Moore SC, Schatzkin A, Hollenbeck AR, van Eijk JT, Leitzmann MF. Joint associations of adiposity and physical activity with mortality: the National Institutes of Health-AARP Diet and Health Study. Am J Epidemiol 2009;169:1344-51.

6. Hu FB, Willett WC, Li T, Stampfer MJ, Colditz GA, Manson JE. Adiposity as compared with physical activity in predicting mortality among women. N Engl J Med 2004;351:2694-703.

7. Bellocco R, Jia C, Ye W, Lagerros YT. Effects of physical activity, body mass index, waist-to-hip ratio and waist circumference on total mortality risk in the Swedish National March Cohort. Eur J Epidemiol 2010;25:777-88.

8. Katzmarzyk PT, Craig CL. Independent effects of waist circumference and physical activity on all-cause mortality in Canadian Women. Appl Physiol Nutr Metab 2006;31:271-6.

9. Hu G, Tuomilehto J, Silventoinen K, Barengo NC, Peltonen M, Jousilahti $P$. The effects of physical activity and body mass index on cardiovascular, cancer and all-cause mortality among 47212 middle-aged Finnish men and women. Int J Obes (Lond) 2005;29:894-902.

10. World Health Organisation [Internet]. BMI classification. [cited 2014 Jan 10]. Available from: http://apps.who.int/bmi/index.jsp?introPage=intro_3. html.

11. National Institutes of Health. Clinical guidelines on the identification, evaluation, and treatment of overweight and obesity in adults. Bethesda (MD): National Heart, Blood, Lung Institute; 1998.

12. Ekelund U, Besson H, Luan J, May AM, Sharp SJ, Brage S, Travier N, Agudo A, Slimani N, Rinaldi S, et al. Physical activity and gain in abdominal adiposity and body weight: prospective cohort study in 288,498 men and women. Am J Clin Nutr 2011;93:826-35.

13. Riboli E, Kaaks R. The EPIC project: rationale and study design. Int $\mathrm{J}$ Epidemiol 1997;26:S6-14.

14. Riboli E, Hunt KJ, Slimani N, Ferrari P, Norat T, Fahey M, Charrondière UR, Hémon B, Casagrande C, Vignat J, et al. European Prospective Investigation into Cancer and Nutrition (EPIC): study populations and data collection. Publ Health Nutr 2002 5(6B):1113-24.

15. Wareham NJ, Jakes RW, Rennie KL, Schuit J, Mitchell J, Hennings S, Day NE. Validity and repeatability of a simple index derived from the short physical activity questionnaire used in the European Prospective Investigation into Cancer and Nutrition (EPIC) study. Public Health Nutr 2003;6:407-13.

16. The InterAct Consortium, Peters T, Brage S, et al. Validity of a short questionnaire to assess physical activity in 10 European countries. Eur J Epidemiol 2012;27:15-25.

17. Haftenberger M, Lahmann PH, Panico S, Gonzalez CA, Seidell JC, Boeing H, Giurdanella MC, Krogh V, Bueno-de-Mesquita HB, Peeters $\mathrm{PH}$, et al. Overweight, obesity and fat distribution in 50-to 64-year-old participants in the European Prospective Investigation into Cancer and Nutrition (EPIC). Public Health Nutr 2002;5(6B):1147-62.

18. Spencer EA, Appleby PN, Davey GK, Key TJ. Validity of self-reported height and weight in 4808 EPIC-Oxford participants. Public Health Nutr 2002;5:561-5.

19. World Health Organisation [Internet]. ICD-10 version 2010. [cited $2014 \mathrm{Feb}$ 1]. Available from: http://apps.who.int/classifications/icd10/browse/2010/en.

20. Rockhill B, Newman B, Weinberg C. Use and misuse of population attributable fractions. Am J Public Health 1998;88:15-9.

21. World Health Organisation [Internet]. Life tables for WHO member states [cited 2014 Aug 10]. Available from: http://www.who.int/healthinfo/ statistics/mortality_life_tables/en/.

22. Haskell WL, Lee IM, Pate RR, Powell KE, Blair SN, Franklin BA, Macera CA, Heath GW, Thompson PD, Bauman A; American College of Sports Medicine. American Heart Association. Physical activity and public health. Updated recommendation for adults from the American College of Sports Medicine and the American Heart Association. Circulation 2007;116:1081-93.

23. Department of Health. Start active, stay active: a report on physical activity from the four home countries' Chief Medical Officers. London; 2011. p. 32-44. 
24. World Health Organisation. Global recommendation on physical activity for health. Geneva (Switzerland): WHO; 2010. p. 23-32.

25. World Health Organisation [Internet]. Global health observatory data repository. 2011 [cited 2013 Aug 20]. Available from: http://apps.who. int/ghodata/.

26. Franco OH, De Laet C, Peeters A, Jonker J, Mackenbach J, Nusselder W. Effects of physical activity on life expectancy with cardiovascular disease. Arch Intern Med 2005;165:2355-60.

27. Barreira TV, Harrington DM, Staiano AE, Heymsfield SB, Smith SR, Bouchard C, Katzmarzyk PT. Anthropometric correlates of total body fat, abdominal adiposity and cardiovascular disease risk factors in a biracial sample of men and women. Mayo Clin Proc 2012; $87: 452-60$.
28. Pischon T, Boeing $H$, Hoffmann K, Bergmann M, Schulze MB Overvad K, van der Schouw YT, Spencer E, Moons KG, Tjønneland A, et al. General and abdominal adiposity and risk of death in Europe. N Engl J Med 2008;359:2105-20.

29. Wang Y, Rimm EB, Stampfer MJ, Willett WC, Hu FB. Comparison of abdominal adiposity and overall obesity in predicting risk of type 2 diabetes among men. Am J Clin Nutr 2005;81:555-63.

30. Yusuf S, Hawken S, Ounpuu S, Bautista L, Franzosi MG, Commerford P, Lang CC, Rumboldt Z, Onen CL, Lisheng L, et al. Obesity and the risk of myocardial infarction in 27,000 participants from 52 countries: a case-control study. Lancet 2005;366:1640-9.

31. Berghöfer A, Pischon T, Reinhold T, Apovian CM, Sharma AM Willich SN. Obesity prevalence for a European perspective: a systematic review. BMC Public Health 2008;8:200. 